УДК 630:582.475.2(470.11)

ВИДОВОЕ РАЗНООБРАЗИЕ РОДА РІСЕА НА ТЕРРИТОРИИ АРХАНГЕЛЬСКОЙ ОБЛАСТИ

${ }^{1}$ Торбик Д.Н., ${ }^{2}$ Власова М.М., ${ }^{2}$ Амосова И.Б.

${ }^{l}$ Филиал ФБУ «Рослесозащита» - «ЦЗЛ Архангельской области», Архангельск, e-mail:dn.torbik@mail.ru;

${ }^{2}$ Северный (Арктический) федеральный университет имени М.В. Ломоносова, Архангельск

Цель исследования - изучение вопроса видового разнообразия рода Picea на территории Архангельской области. В статье проведен сравнительный анализ макроконстробилов (женских шишек) ели, собранных в 8 районах Архангельской области, на предмет их видовой принадлежности. Основные признаки, идентифицирующие Picea abies, Picea obovata и Picea x fennica, определены в результате анализа доступных литературных источников. Растительный материал (шишки) отбирался в разных районах области в ельниках зеленомошного типа, как наиболее распространённого типа леса исследуемой территории. Проанализированы морфометрические параметры шишки (соотношение длины и ширины), форма семенных чешуй, их размеры и количество. Для проведения статистического анализа использовалась прикладная компьютерная программа для обработки данных SPSS Statistics. Результаты исследования показали, что распределение условных групп видов в исследуемых выборках не однородное. В каждой выборке обнаружены шишки с признаками ели гибридной. Наибольший процент Picea $x$ fennica зафиксирован в Вельском, Шенкурском, Котласском и Лешуконском районах. Наибольший процент образцов, которые имели признаки, близкие к Picea obovata, наблюдается в выборках с юго-востока области (Ленский, Красноборский районы). С продвижением на северо-запад доля Picea obovata в выборках заметно снижается, но возрастает участие Picea abies. Tак, в Шенкурском районе не обнаружено шишек видовой группы obovata, а участие Picea abies в формировании выборки составило 26,7\%. В Онежском районе нами зафиксировано максимальное число образцов с признаками Picea abies - 62,6\%. Полученные данные не противоречат имеющимся в литературе данным.

Ключевые слова: видовое разнообразие, ель, интрогрессивная гибридизация, Picea $x$ fennica, Picea obovata, Picea abies

\title{
SPECIES DIVERSITY OF THE GENUS PICEA IN THE ARKHANGELSK REGION
}

${ }^{1}$ Torbik D.N., ${ }^{2}$ Vlasova M.M., ${ }^{2}$ Amosova I.B.

${ }^{1}$ Branch of the FBU «Russian Centre of Forest Health» - «CFH of the Arkhangelsk region», Arkhangelsk,e-mail:dn.torbik@mail.ru;

${ }^{2}$ Northern (Arctic) Federal University named after M.V. Lomonosov, Arkhangelsk

The purpose of the study is to study the issue of species diversity the genus Picea in the Arkhangelsk region. The article presents a comparative analysis of macroconstrobils (female cones) of spruce collected in 8 districts of the Arkhangelsk region for their species. The main features identifying Picea abies, Picea obovata, and Picea $x$ fennica were determined by analyzing available literature sources. Plant material (cones) was selected in different regions of the region in spruce forests of the green moss type, as the most common type of forest in the study area. The morphometric parameters of the cone (the ratio of length and width), the shape of seed scales, their size and number are analyzed. The statistical analysis was performed using an applied computer program for data processing SPSS Statistics. The results of the study showed that the distribution of conditional groups of species in the studied samples is not uniform. In each sample, cones with signs of hybrid spruce were found. The largest percentage of Picea $x$ fennica was recorded in the Velsky, Shenkursky, Kotlassky and Leshukonsky districts. The largest percentage of samples that had characters close to Picea obovata is observed in samples from the southeast of the region (Lensky, Krasnoborsky districts). Moving to the northwest, the proportion of Picea obovata in the samples noticeably decreases, but the proportion of Picea abies increases. Thus, no cones of the obovata species group were found in the Shenkurskiy district, and the participation of Picea abies in the formation of the sample was $26,7 \%$. In the Onega region, we recorded the maximum number of samples with Picea abies characters $-62,6 \%$. The data obtained do not contradict the data available in the literature.

Keywords: species diversity, spruce, introgressive hybridization, Picea $x$ fennica, Picea obovata, Picea abies

Вопрос видового разнообразия рода $P i$ сеа привлекает внимание исследователей уже давно. До сих пор ученые не пришли к единому мнению в вопросе самостоятельности Picea $x$ fennica (Regel) Kom как вида. Изучение рода Picea в зоне интрогрессивной гибридизации на всех уровнях видового разнообразия поможет дать четкую картину о процессах, происходящих внутри популяций, и спрогнозировать дальнейшие пути их развития.
Лесистость Архангельской области без учёта безлесных арктических островов Белого моря, Северного Ледовитого океана и Новой Земли составляет 72,3\%. На долю хвойных насаждений приходится 76,1\% лесного фонда, из которых более $64,8 \%$ - ель [1].

Таксономическое положение рода Picea в Архангельской области до конца не определено. С XIX века считалось, что частью границы ареалов P. abies (L.) Karst. и $P$. ob- 
ovata Ledeb. является Северная Двина. Позже было отмечено, что по обе стороны Северной Двины широко распространены гибридные популяции указанных видов ели $[2 ; 3]$. На сегодняшний день большинство ученых [4-6] придерживается теории интрогрессивной гибридизации, предложенной Бобровым Е.Г. (1978) [7], согласно которой Архангельская область является территорией, где происходит процесс гибридизации между P. abies и P. obovata, поэтому подавляющее большинство особей являются гибридными формами.

Цель наших исследований - изучение вопроса видового разнообразия рода Picea на территории Архангельской области.

\section{Материалы и методы исследования}

При помощи сайта Plant List.com [8] изучены списки утвержденных на настоящий момент названий видов рода Picea. Выявлены основные виды елей на территории России и Архангельской области [9; 10]. Для поиска идентификационных признаков видов рода Picea был проведен анализ различных определителей растений и работ по теме исследования [11-13].

Изучение растительного материала произведено с использованием общепринятых в ботанике методик на 8 выборках женских шишек из разных районов Архангельской области (по 4 выборки с каждой стороны p. Северная Двина) (рис. 1).

Для каждой шишки по основным морфологическим признакам определяли видовую принадлежность, измеряли длину и ширину, подсчитывали число семенных чешуй, фиксировали размеры с пяти чешуек из средней части макроконстробила, обращая внимание на форму нижнего края.

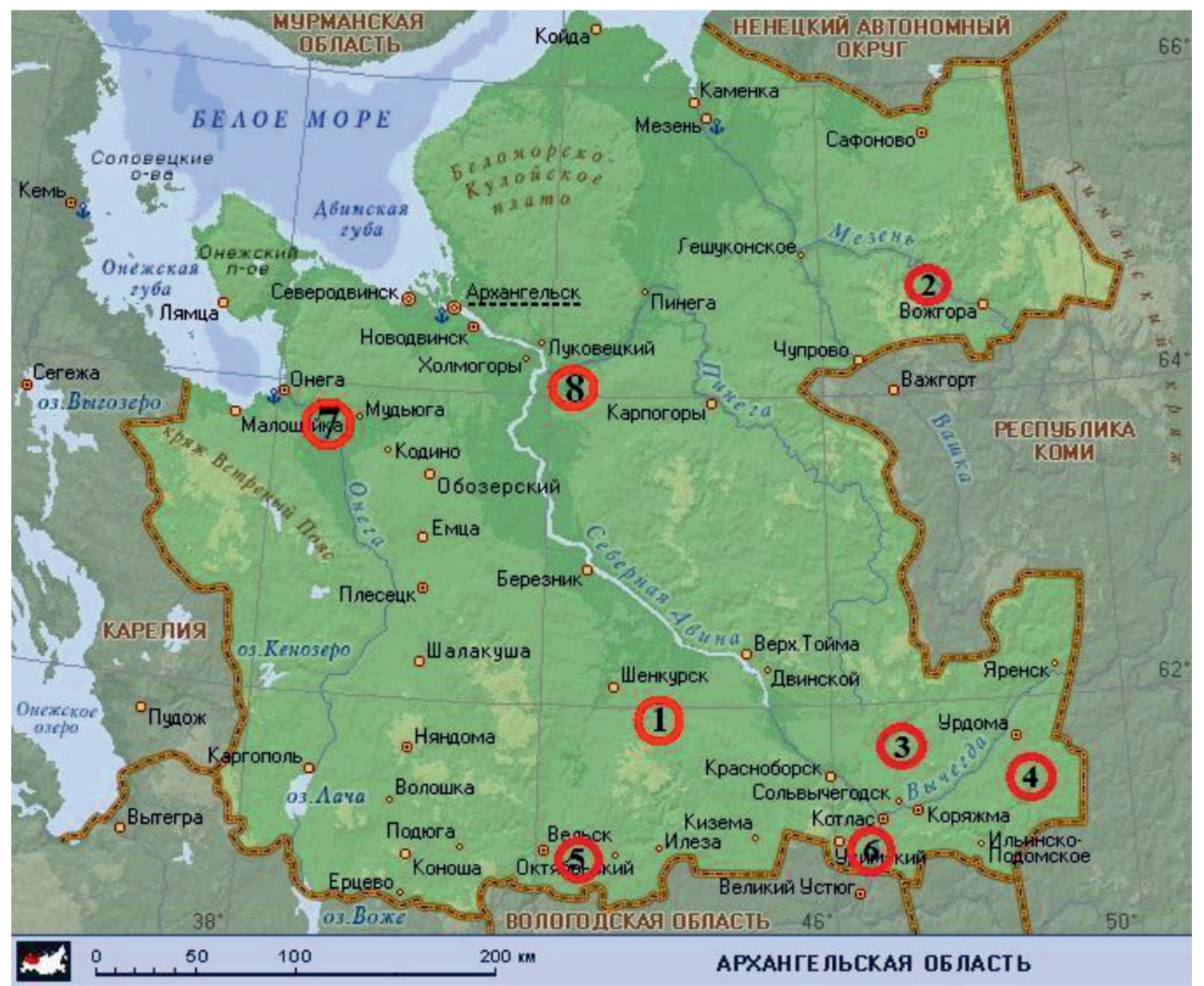

Рис. 1. Точки сбора образцуов шишек рода Рісеа на территории Архангельской области (1 - Шенкурский р-н; 2 - Лешуконский р-н; 3 - Красноборский $p$-н; 4 - Ленский $p$-н; 5 - Вельский р-н; 6 - Котласский р-н; 7 -Онежский р-н; 8 -Холмогорский $p$-н) 


\section{Результаты исследования и их обсуждение}

Собранные образцы изучались на предмет видовой принадлежности согласно табл. 1. Все образцы в 8 выборках были условно разделены на три группы:

1 - Picea abies, сюда попали образцы шишек с ярко выраженными признаками Picea abies;

2 - Picea obovata, к этой группе отнесли те шишки, которые имеют признаки, близкие, по данным определителей, к Picea obovata;

3 - Picea $x$ fennica, в этой группе оказались те образцы, видовую принадлежность которых было сложно определить, так как они имеют признаки как P. abies, так и P. obovata.

Распределение Picea abies, P. obovata, и P. $x$ fennica в исследуемых выборках отражено в табл. 2.

В результате подавляющее большинство шишек, собранных на территории Вельского района, имеет признаки Picea $x$ fennica $(73,3 \%)$. Число шишек с признаками Picea abies наблюдалось почти в 10 раз меньше $-6,67 \%$. Данный регион, по работам Правдина (1975) [2] и Боброва (1978) [7], находится в центре зоны интрогрессивной гибридизации, это объясняет большой процент гибридных особей в выборке.

Сравнительный анализ диагностических и морфометрических

Таблица 1 признаков видов рода Picea

\begin{tabular}{|c|c|c|c|}
\hline Признак & Picea abies (L.) H. Karst. & Picea obovata Ledeb. & Picea x fennica (Regel) Kom. \\
\hline \multicolumn{4}{|c|}{ Диагностические признаки генеративных структур - литературные данные } \\
\hline $\begin{array}{l}\text { Макро } \\
\text { строб }\end{array}$ & $\begin{array}{l}\text { Молодые шишки на кон- } \\
\text { цах двухлетних побегов } \\
\text { удлиненно-цилиндриче- } \\
\text { ские, ярко-красные, позд- } \\
\text { нее становятся зелеными, } \\
\text { а перед созреванием бу- } \\
\text { реют. Зрелые - висячие } \\
10-16 \text { см длиной и 3-4 см } \\
\text { шириной, чешуи их об- } \\
\text { ратнояйцевидные, выпу- } \\
\text { клые, по краю волнистые } \\
\text { или выгрызено-зубча- } \\
\text { тые [9; 10] }\end{array}$ & $\begin{array}{l}\text { Молодые шишки, одиночные, } \\
\text { овально-цилиндрические, 13- } \\
20 \text { мм. Зрелые шишки бурые, } \\
\text { продолговато-яйцевидные или } \\
\text { яйцевидно-цилиндрические, } \\
\text { висячие, длиной 5-8 см, чешуи } \\
\text { их 11-15 мм длиной и шири- } \\
\text { ной, почти почковидные, с ши- } \\
\text { роко-клиновидным основанием } \\
\text { и полого-закругленным, почти } \\
\text { цельнокрайним верхним кра- } \\
\text { ем, по внутренней свободной } \\
\text { от семян поверхности усажены } \\
\text { короткими волосками [9] }\end{array}$ & $\begin{array}{l}\text { Шишки длиной 6-10 см, ши- } \\
\text { риной 3,5-4,5 см, обратно-яй- } \\
\text { цевидно-цилиндрические или } \\
\text { обратнояйцевидные, с варьиру- } \\
\text { ющей формой основания шиш- } \\
\text { ки. Семенные чешуи 13-23 мм } \\
\text { длиной и 13-22 мм шириной, } \\
\text { обратнояйцевидные или широ- } \\
\text { ко-обратнояйцевидные. Крою- } \\
\text { щие чешуи 4,8-8 мм длиной, } \\
\text { шириной 1,77-3 мм, треуголь- } \\
\text { ные, ромбические или широко- } \\
\text { ланцетные с опушенными че- } \\
\text { шуями верхушечных почек [11] }\end{array}$ \\
\hline Семена & \begin{tabular}{|lr} 
Семена & яйцевидные, \\
острые, тёмно-бурые, 4 \\
мм длиной, крыло их жёл- \\
то-красное, в 3 раза длин- \\
нее их [9]
\end{tabular} & $\begin{array}{l}\text { Семена } 4 \text { мм длиной, косо-об- } \\
\text { ратнояйцевидные. Крыло 1-1.5 } \\
\text { см длиной, 4-5 мм шириной [9] }\end{array}$ & $\begin{array}{l}\text { Семена мельче, чем у } P \text {. abies, } \\
\text { и дают медленно растущие, но } \\
\text { очень выносливые сеянцы [7; } \\
11]\end{array}$ \\
\hline
\end{tabular}

Таблица 2

Распределение Picea abies, P.obovata и P. x fennica в исследуемых выборках

\begin{tabular}{|l|c|c|c|}
\hline \multirow{2}{*}{ Выборка/Вид } & \multicolumn{3}{|c|}{ Количество шишек, \% } \\
\cline { 2 - 4 } & Picea abies & Picea obovate & Picea x fennica \\
\hline Вельская & 6,67 & 13,3 & 73,3 \\
\hline Шенкурская & 26,7 & 0,0 & 73,3 \\
\hline Котласская & 20,0 & 33,3 & 46,7 \\
\hline Ленская & 33,3 & 40,0 & 26,7 \\
\hline Красноборская & 13,4 & 53,3 & 33,3 \\
\hline Лешуконская & 20,0 & 26,7 & 53,3 \\
\hline Холмогорская & 0,0 & 46,7 & 53,3 \\
\hline Онежская & 63,6 & 9,1 & 27,3 \\
\hline
\end{tabular}


В выборке Шенкурского района были выделены две группы: P. abies и P. x fennica. Образцов ели сибирской в данной выборке обнаружено не было. Большую часть выборки составляют шишки ели гибридной $(73,3 \%)$. Образцов ели европейской в Шенкурском районе в 2 раза меньше - 26,7\%. Отсутствие ели сибирской в выборке Шенкурского района может быть теоретически обосновано интрогрессивной гибридизацией, а также особенностью отбора проб. Иначе говоря, в обхват территории, где проводился отбор проб, не попали особи Picea obovata. Однако часть гибридных образцов шишек имеют форму семенных чешуй, близкую к P. obovata.

В результате изучения видового разнообразия в Котласском районе выделены группы образцов с признаками всех трёх групп (Picea abies, P. obovata и P. x fennica). Больше всего в данной выборке присутствовали шишки с признаками ели гибридной - 46,7\%, в два раза меньше было выявлено шишек с признаками ели европейской $-20 \%$, оставшиеся $33,3 \%$ пришлись на экземпляры с признаками ели сибирской. Образцы, которые нами были идентифицированы как гибридные, имели форму семенных чешуй, близкую к Picea obovata, но с вытянутым зубчатым краем.

В выборке Ленского района преобладает ель с признаками Picea obovate (40\%). Ярко выраженные признаки Picea abies имели $33,3 \%$ шишек. Число гибридных форм было немногим меньше $-26,7 \%$. Образцы шишек, которые были отнесены к группе Picea $x$ fennica, имели форму семенных чешуй, близкую к Picea obovate.

Красноборские образцы, как и в выборке Ленского района, в половине случаев имели признаки Picea obovata - 53,3\%. Шишек с признаками Picea x fennica выявлено 33,3\%. Так как по территории данного района проходит граница зоны интрогрессивной гибридизации и с востока, согласно историческим сводкам, двигалась ель сибирская, большой процент образцов, по морфологическим признакам близких к ели сибирской, в выборке вполне вероятен. Гибридная форма шишек в данной выборке по морфологическим признакам также близка к ели сибирской.

По результатам исследований, на долю образцов с признаками Picea abies в Лешуконском районе приходится $20 \%$, на долю Picea obovate - 26,7\%. Процент особей с признаками как ели сибирской (в большей степени), так и европейской, которые составили группу Picea $x$ fennica в данной выборке $-53,3 \%$.
В выборке Холмогорского района не выявлено образцов с признаками ели европейской. Больше половины образцов были идентифицированы как P. x fennica $-53,3$ \%, так как край семенной чешуи был зубчатый, а размер этих шишек, по данным определителей, соизмерим с размерами шишек ели сибирской, процент которой в выборке составил $46,7 \%$.

После изучения шишек выборки из Онежского района на предмет видовой принадлежности оказалось, что почти $64 \%$ имеют ярко выраженные морфологические признаки P. abies. В то время как доля ели сибирской составила 9\%. Процент гибридных особей составил $27,3 \%$. Онежский район расположен на западе от Северной Двины, которая является условной границей соприкосновения ели европейской и сибирской, в связи с этим вполне вероятно большее число особей ели европейской на данной территории.

В целом по полученным данным, почти половина изученных нами шишек имеют признаки Picea $x$ fennica. Так, в четырех выборках доля гибридных форм больше половины, а в остальных составляет около 1/3. В трех выборках высокую долю имеют образцы Picea obovate, в среднем на них приходится $30 \%$. Женские шишки с признаками Picea abies доминируют только в одной выборке, а в остальных занимают менее 1/3. На долю этого вида приходится $21 \%$ всех изученных образцов шишек (рис. 2).

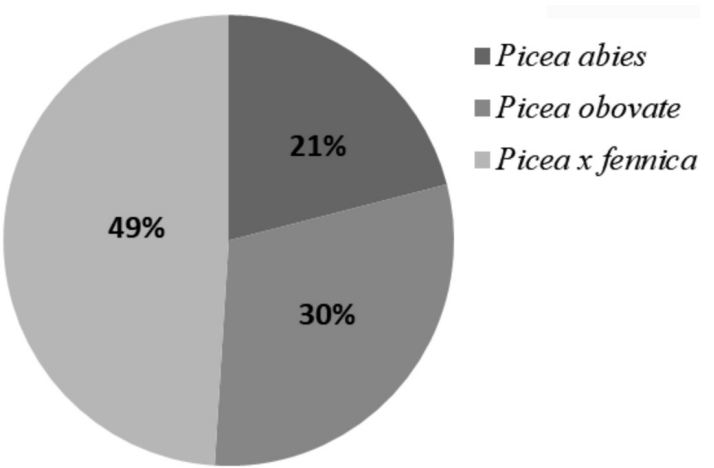

Рис. 2. Общее распределение исследованных образиов по группам Picea

Для проведения статистического анализа мы воспользовались прикладной компьютерной программой для статистической обработки данных SPSS Statistics. Полученные показатели рассматривали и анализировали в отдельности для каждого вида по средним данным морфометрических признаков (табл. 3). 
Таблица 3

Сравнительный анализ диагностических признаков по морфометрическим параметрам

\begin{tabular}{|l|c|c|c|}
\hline \multicolumn{1}{|c|}{ Признак } & $\begin{array}{c}\text { Picea abies (L.) } \\
\text { H. Karst. }\end{array}$ & Picea obovata Ledeb. & $\begin{array}{c}\text { Picea } x \text { fennica } \\
\text { (Regel) Kom. }\end{array}$ \\
\hline Длина шишек, см & $8,973 \pm 0,569$ & $7,220 \pm 0,232$ & $8,08 \pm 0,185$ \\
\hline Ширина шишек, см & $4,000 \pm 0,131$ & $3,387 \pm 0,132$ & $2,91 \pm 0,643$ \\
\hline Количество семенных чешуй, шт. & $108,2 \pm 7,008$ & $111,3 \pm 2,909$ & $127,3 \pm 4,160$ \\
\hline Длина семенной чешуи, мм & $18,13 \pm 0,232$ & $16,33 \pm 0,284$ & $17,05 \pm 0,158$ \\
\hline Ширина семенной чешуи, мм & $14,95 \pm 0,136$ & $14,08 \pm 0,181$ & $14,11 \pm 0,198$ \\
\hline
\end{tabular}

По результатам измерений морфологических показателей шишек, отнесённых к разным видам рода Picea согласно табл. 1, было установлено, что образцы Picea $x$ fennica отличаются от Picea abies и Picea obovate по всем исследуемым параметрам. Средняя длина шишек, семенных чешуй и ширина семенных чешуи изученных образцов составляют 8,08 см, 17,05 мм и 14,11 мм соответственно и представляют собой средние значения между соответствующим показателями Picea abies и Picea obovate. Ширина шишек составляет 2,9 см - минимальное значение, а количество семенных чешуй (127,3 шт.) - наибольшее значение для сравниваемых показателей. Полученные показатели согласуются с литературными данными по морфометрическим параметрам шишек различных видов рода Picea, представленными в табл. 1.

\section{Заключение}

Распределение условных групп видов в исследуемых выборках было не однородное. В каждой выборке обнаружены шишки с признаками ели гибридной. Наибольший процент образцов, которые имели признаки, близкие к Picea obovata, наблюдается в выборках с юго-востока области (Ленский, Красноборский районы). С продвижением на северо-запад доля Picea obovata в выборках заметно снижается, но возрастает участие Picea abies. В Онежском районе зафиксировано максимальное число образцов с признаками Picea abies - 62,6\%. Результаты нашей работы в целом подтверждают мнения различных исследователей о распространении Picea abies, Picea obovata и Picea $x$ fennica на Северо-Западе России $[6 ; 7 ; 10]$.

\section{Список литературы / References}

1. Лесной план Архангельской области, 2018. [Электронный ресурс]. URL: https://portal.dvinaland.ru/upload/ iblock/36f/Lesnoj \%20plan \%20Arhangelskoj \%20oblasti \%20 2019-2028.pdf (дата обращения: 28.11.2020).
Forest plan of the Arkhangelsk region, 2018. [Electronic resource]. URL: https://portal.dvinaland.ru/upload/iblock/36f/ Lesnoj \%20plan \%20Arhangelskoj \%20oblasti \%202019-2028. pdf (date of access: 28.11.2020) (in Russian).

2. Правдин Л.Ф. Ель европейская и ель сибирская в СССР. М.: Наука, 1975. 176 с.

Pravdin L.F. European Spruce and Siberian spruce in the USSR. M.: Nauka, 1975. 176 p. (in Russian).

3. Попов П.П. Формовая структура и географическая дифференциация популяций ели на северо-западе России // Экология. 2010. № 5. С. 336-343.

Popov P.P. Form structure and geographical differentiation of spruce populations in the North-West of Russia // Ekologiya. 2010. No. 5. P. 336-343 (in Russian).

4. Егоров А.А., Бурцев Д.С., Орлова Л.В., Николаева М.А. Продуктивность видов и внутривидовых таксонов Picea abies, P. fennica, P. obovata в географических культуpax на Северо-Западе России // Уч. записки Петрозаводского гос. ун-та. 2011. Т. 121. № 8. С. 59-64.

Egorov A.A., Burtsev D.S., Orlova L.V., Nikolaeva M.A. Productivity of species and intraspecific taxa Picea abies, P. fennica, P. obovata in geographical cultures in the North-West of Russia// Uch. zapiski Petrozavodskogo gos. un-ta. 2011. Vol. 121. No. 8. P. 59-64 (in Russian).

5. Ильинов А.А., Раевский Б.В., Рудковская О.А., Топчиева Л.В. Сравнительная оценка фенотипического и генетического разнообразия северотаежных малонарушенных популяций ели финской (Picea $\times$ fennica) // Тр. Карельского науч. центра РАН. 2011. Т. 1. С. 37-47.

Ilyin A.A., Raevsky B.V., Rudkovskaja O.A., Topchieva L.V. Comparative assessment of the phenotypic and genetic diversity of Northern taiga intact populations of Finnish spruce (Picea $\times$ fennica) // Tr. Karel'skogo nauch. tsentra RAN. 2011. Vol. 1. P. 37-47 (in Russian).

6. Тарханов С.Н. Популяционная изменчивость ели финской по форме семенных чешуй на севере Архангельской области // Лесоведение. 2019. № 3. С. 208-2014.

Tarkhanov S.N. Population variability of Finnish spruce in the form of seed scales in the North of the Arkhangelsk region // Lesovedeniye. 2019. No. 3. P. 208-2014 (in Russian).

7. Бобров Е.Г. Лесообразующие хвойные СССР. Л., 1978. $64 \mathrm{c}$.

Bobrov E.G. forest-Forming conifers of the USSR. L., 1978. 64 p. (in Russian).

8. The Plant List (2013). Version 1.1. Published on the Internet; http://www.theplantlist.org/ (англ.), 2013. [Electronic resource]. URL: http://www.theplantlist.org/ (date of access: 21.11.2020).

9. Флора северо-востока европейской части СССР. Т. I Семейства Polypodiaceae - Gramineae / Под. ред. А.И. Толмачева. Л.: Наука, 1974. 275 с

Flora of the north-east of the European part of the USSR. T. I of the Family Polypodiaceae - Gramineae/ Pod. red. A.I. Tolmacheva. L.: Nauka, 1974. 275 p. (in Russian).

10. Губанов И.А., Киселева К.В., Новиков В.С., Тихомиров В.Н. Иллюстрированный определитель растений Средней 
России. Том 1. Папоротники, хвощи, плауны, голосеменные, покрытосеменные (однодольные). М., 2002. 528 с.

Gubanov I.A., Kiseleva K.V., Novikov V.S., Tikhomirov V.N. Illustrated determinant of plants in Central Russia. Volume 1. Ferns, horsetails, plaunae, gymnosperms, angiosperms (monocotyledons). M., 2002. 528 p. (in Russian).

11. Орлова Л.В., Егоров А.А. К систематике и географическому распространению ели финской (Picea fennica (Regel) Kom., Pinaceae)// Новости систематики высших растений. СПб.: Ботанический институт им. В.Л. Комарова РАН. 2010. Т. 42. С. 5-23.

Orlova L.V., Egorov A.A. On the systematics and geographical distribution of Finnish spruce (Picea fennica (Regel) Kom., Pinaceae) // Novosti sistematiki vysshikh rasteniy. SPb.:
Botanicheskiy institut im. V.L. Komarova RAN. 2010. Vol. 42. P. 5-23 (in Russian).

12. Синицын Е.M. Определитель голосеменных древесных растений: учебное пособие. СПб.: Лань, 2019. 184 с.

Sinitsyn E.M. Determinant of gymnosperms of woody plants: textbook. SPb.: Lan', 2019. 184 p. (in Russian).

13. Попов П.П. Соотношение показателей длины шишек и формы семенных чешуй в популяциях Piceae abies и P. obovata (Pinaceae) // Ботанический журнал. 2012. Т. 97. № 6. C. 729-734.

Popov P.P. Ratio of indicators of the length of cones and the shape of seed scales in populations of Picea abies and $P$ obovata (Pinaceae) // Botanicheskiy zhurnal. 2012. Vol. 97. No. 6. P. 729-734 (in Russian) 